\title{
Carbon Dioxide Sequestration in Concrete and its Effects on Concrete Compressive Strength
}

\author{
Zarina Itam, Mohd Hafiz Zawawi, Yuovendra Sivaganese, Salmia Beddu, Nur Liyana Mohd Kamal \\ Department of Civil Engineering, College of Engineering, Universiti Tenaga Nasional, Jalan IKRAM- \\ UNITEN, 40300 Kajang, Selangor, Malaysia. \\ iZarina@uniten.edu.my
}

\begin{abstract}
In recent years, the production of cement has grown globally in a very rapid manner due to the modernization of the world we live in, and after fossil fuels and land-use change, cement production is the third-largest source of anthropogenic emissions of carbon dioxide, $\mathrm{CO}_{2}$. Cement being the primary binding material for concrete and with the prospects for the concrete industry continues to grow so will the emissions of $\mathrm{CO}_{2}$. Hence, a method to reduce the $\mathrm{CO}_{2}$ production while keeping up with the progression of the concrete industry is very crucial in current times. This is where $\mathrm{CO}_{2}$ sequestration comes in. It is a process where $\mathrm{CO}_{2}$ is converted into a mineral which will then be trapped into the concrete forever. Required data to carry out the research between $\mathrm{CO}_{2}$ sequestered concrete and concrete without $\mathrm{CO}_{2}$ have been observed, obtained and tabulated as necessary. These data are then used to compare the concrete samples with one another and also prove the theoretical effects of $\mathrm{CO}_{2}$ exposure to concrete. Hence, experimental results on the compressive strength of the concrete samples for 7, 14 and 28 days has also been tabulated, graphed and further disputed. The objective of this research is mainly to determine the compressive strength of $\mathrm{CO}_{2}$ sequestered concrete in comparison with concrete without $\mathrm{CO}_{2}$ in order to decrease the effects the concrete industry has on the environment. The compressive strength of concrete samples with sequestration of $\mathrm{CO}_{2}$ gas is expected to be higher than of the concrete without $\mathrm{CO}_{2}$.
\end{abstract}

Keywords: Sequestration, Carbon Dioxide, Concrete strength

\section{INTRODUCTION}

Cement, being the main binding material for concrete that has been used since ancient times together with the increasing rate of modernization of the world, the emission of $\mathrm{CO}_{2}$ in the construction industry is bound to increase. There are two parts of bond creation that outcome in emission of $\mathrm{CO}_{2}$. The first during the production of the primary parts of concrete, clinker, as carbonates are decayed to form oxides. There have been studies that show that these process discharges contribute about $5 \%$ of anthropogenic $\mathrm{CO}_{2}$ outflows. The second source of emission of is the combustion of $\mathrm{CO}_{2}$ through heat. This happens during fossil fuels are set to burn in order to produce significant energy. The energy here is then taken into account to heat the raw ingredients. Total emissions from the cement industry could therefore contribute as much as $8 \%$ of global $\mathrm{CO} 2$ emissions [1].

Hence it is evident that carbon footprint has been a prolonged problem in recent days especially in the construction industry. Production of concrete is one of the main contributors of this problem in the industry. Sequestering $\mathrm{CO}_{2}$ will ultimately convert $\mathrm{CO}_{2}$, the major constituent of the greenhouse gases into a mineral which will then be trapped into concrete forever. Sequestered $\mathrm{CO} 2$ in concrete can provide an impact on reducing the carbon footprint and also to improve the compressive strength of concrete. On a bigger scale, this would entirely change the construction industry [2].

Various experimental evidences can be found from literature on curing by carbonation. But it has always been related to the reduction of calcium hydroxide. Because of this, it becomes useful to durability improvement such as resistance to sulphate attack and efflorescence. However, there is concern that reduced calcium hydroxide may promote more carbonation depth when it comes to carbonation due to weathering. The reaction of carbon dioxide with concrete that is mature has effects such as reduced pore solution, $\mathrm{pH}$ value, and corrosion. In contrast, a carbonation reaction during the early stages of producing concrete, in this case during the mixing phase does not have the same effects.

Concrete carbonation is the entire process that takes place during the sequestration of $\mathrm{CO}_{2}$ in concrete [3]. Early carbonation does not cause a negative impact on the long-term development of concrete as compared 
to weathering carbonation. This is because early age carbonation occurs when the carbonation reactions occur alongside the early hydration of the cement through a deliberate exposure of fresh concrete to $\mathrm{CO}_{2}$ [4].

Calcium silicate in the cement when mixed with water produces two things, calcium carbonate and calcium silicate hydrate gel. During this phase, $\mathrm{Ca}^{2+}$ ions are formed. Therefore, when $\mathrm{CO}_{2}$ is sprayed at the wet concrete, hydration occurs to produce $\mathrm{H}_{2} \mathrm{CO}_{3}$. The ionisation of $\mathrm{H}_{2} \mathrm{CO}_{3}$ then produces $\mathrm{H}^{+}, \mathrm{HCO}_{3}{ }^{-}$and $\mathrm{CO}_{3}{ }^{2-}$. Exothermic reaction takes place between $\mathrm{Ca}^{2+}$ and $\mathrm{CO}_{3}{ }^{2-}$ to form the $\mathrm{CaCO}_{3}$ in solid form [5].

$$
\mathrm{Ca}(\mathrm{OH})_{2}+\mathrm{CO}_{2} \longrightarrow \mathrm{CaCO}_{3}+\mathrm{H}_{2} \mathrm{O}
$$

The final product of this chemical reaction is the nanosized $\mathrm{CaCO}_{3}$ filling the voids in the concrete. The effects of nanosized $\mathrm{CaCO}_{3}$ has been evident in other researches. A study has shown that the utilization of nanosized $\mathrm{CaCO}_{3}$ to $4 \%$ can diminish the fatigue of hot mix asphalt. Additionally, it was discovered that the addition of nanosized $\mathrm{CaCO}_{3}$ can increase moisture damage potential. For the indirect tensile fatigue test, the results show that nanosized $\mathrm{CaCO}_{3}$ modified asphalt mixture improves pavement performance by providing additional resistance to the primary distresses in flexible pavements. Fatigue is induced by tension, and thus an improvement in the tensile strength property of the mix is seen as improvement in fatigue resistance [6]. For the dynamic creep test, it was observed that mixtures with nanosized $\mathrm{CaCO}_{3}$ have less permanent deformation compared to those without nanosized $\mathrm{CaCO}_{3}$. It also improved the tensile strength of the hot asphalt. As the amount of nanosized $\mathrm{CaCO}_{3}$ exceeds the permanent deformation decreases as it reaches $4 \%$ of nanosized $\mathrm{CaCO}_{3}$.

Despite all these benefits, the main reason the doubt still exists is because of the cost of producing carbon dioxide gas. But this obstacle is bound to be removed in the near future as recovered $\mathrm{CO}_{2}$ is expected to become available at low cost and could also act as a curing agent in concrete plants to replace steam in the precast concrete production [7]. Besides that, the development of large-scale carbon capture systems in status quo can also reduce this cost as $\mathrm{CO}_{2}$ of high purity becomes a by-product from hydrocarbon-based power generation or cement production [8].

\section{MATERIALS AND METHODS}

\section{A. Parameters}

The type of $\mathrm{CO}_{2}$ gas used was from a pure $\mathrm{CO}_{2}$ gas cylinder instead of flue gas where the $\mathrm{CO}_{2}$ content is lower. With pure $\mathrm{CO}_{2}$ gas cylinders, the results will be more effective since there is only one type of gas introduced unlike flue gas where multiple gasses are involved. The only thing with pure $\mathrm{CO}_{2}$ gas cylinders is that they are way more expensive compared to flue gas cylinders. A gas regulator is used to control the $\mathrm{CO}_{2}$ has to also be determined in order to ensure an adequate flow of $\mathrm{CO}_{2}$ gas. Hence, a regulator with both flow rate and pressure is used to comprehend the manipulated variable. Also, to be added since the amount of $\mathrm{CO}_{2}$ gas used is small for this small scaled project, the regulator is off very small value ranges for both the pressure and flow rate.

The concrete mixer is of an enclosed one in order to allow effective mixing of the $\mathrm{CO}_{2}$ and the mix. A cylinder of $\mathrm{CO}_{2}$ with a flow meter and a small hose is attached to the nozzle of the cylinder. The hose is then placed into the mixer. The opening of the mixer was fully enclosed and sealed air tight with only a small opening to fit in the hose that's attached to the carbon dioxide cylinder. The $\mathrm{CO}_{2}$ was sprayed at a specific flow rate into the concrete mixer. The duration for the $\mathrm{CO}_{2}$ to be sprayed was for 3 to 5 minutes of the entire concrete mixing time. To allow some comparison, a sample with higher duration of $\mathrm{CO}_{2}$ exposure of 30 mins was also added.

Samples of concrete mix with and without $\mathrm{CO}_{2}$ were prepared. The grade of concrete designed was of Grade 30 for all the samples. The mixed concrete is then placed in cube moulds measuring $10 \mathrm{~cm} \times 10 \mathrm{~cm} \times 10 \mathrm{~cm}$. The test specimens are then stored in moist air for 24 hours and after this period the samples are marked according to their design ratio and removed from the moulds and kept submerged in clear fresh water until taken out for testing, this would be at three different times, 7 days 14 days, and 28 days for the density and the compressive strength of the concrete. 
TABLE I. CONCRETE MiX PARAMETERS

\begin{tabular}{|c|c|c|c|}
\hline $\begin{array}{c}\text { Concrete } \\
\text { Mixture }\end{array}$ & $\begin{array}{c}\text { Concrete } \\
\text { Grade }\end{array}$ & Presence of $\mathrm{CO}_{2}$ gas & Duration of $\mathrm{CO}_{2}$ gas injection \\
\hline A & 30 & Absent & - \\
\hline B & 30 & Present & $25-30$ mins \\
\hline C & 30 & Present & $3-5$ mins \\
\hline
\end{tabular}

\section{B. Theories and Assumptions}

Based on observation, after determining the mix design of the concrete samples the concrete mixture that had $\mathrm{CO}_{2}$ injected during the mixing phase seemed to be drier than of the concrete without $\mathrm{CO}_{2}$. The reason behind this reduction of water are possibly two things. One being that the duration that the $\mathrm{CO}_{2}$ gas was introduced was longer than required another is that due to the reaction that occurred between the $\mathrm{CO}_{2}$ gas that was introduced and the fresh concrete in order to produce nanosized $\mathrm{CaCO}_{3}$. With the addition of more water, the compressive strength of the concrete with $\mathrm{CO}_{2}$ could possibly be higher. The duration of $\mathrm{CO}_{2}$ gas was reduced to 3 to 5 mins depending on the duration it takes to mix the concrete from initially being 30 mins which usually is the time taken for $\mathrm{CO}_{2}$ cured concrete.

\section{RESULTS AND DISCUSSIONS}

The density of the concrete samples reflects back on the presence of $\mathrm{CO}_{2}$ and also the duration the $\mathrm{CO}_{2}$ is exposed to the concrete mixture. Due to the reduction of water of the samples with $\mathrm{CO}_{2}$ gas present had the lowest density while the samples with $\mathrm{CO}_{2}$ present had the highest density. This is probably because of the nanosized $\mathrm{CaCO}_{3}$ formed during the reaction that fill up the pores of the concrete samples. The table and the graph below portray the difference between the densities amongst the samples.

TABLE II. DENSITY OF CONCRETE SAMPLES

\begin{tabular}{|c|c|c|c|c|c|}
\hline Concrete Mix & \multicolumn{3}{|c|}{ Density $\left(\mathrm{kg} / \mathrm{m}^{3}\right)$} & Average Density \\
\hline A & 2417 & 2413 & 2422 & 2420 & $2418 \mathrm{~kg} / \mathrm{m}^{3}$ \\
\hline B & 2379 & 2367 & 2384 & 2370 & $2375 \mathrm{~kg} / \mathrm{m}^{3}$ \\
\hline C & 2425 & 2420 & 2419 & 2428 & $2423 \mathrm{~kg} / \mathrm{m}^{3}$ \\
\hline
\end{tabular}




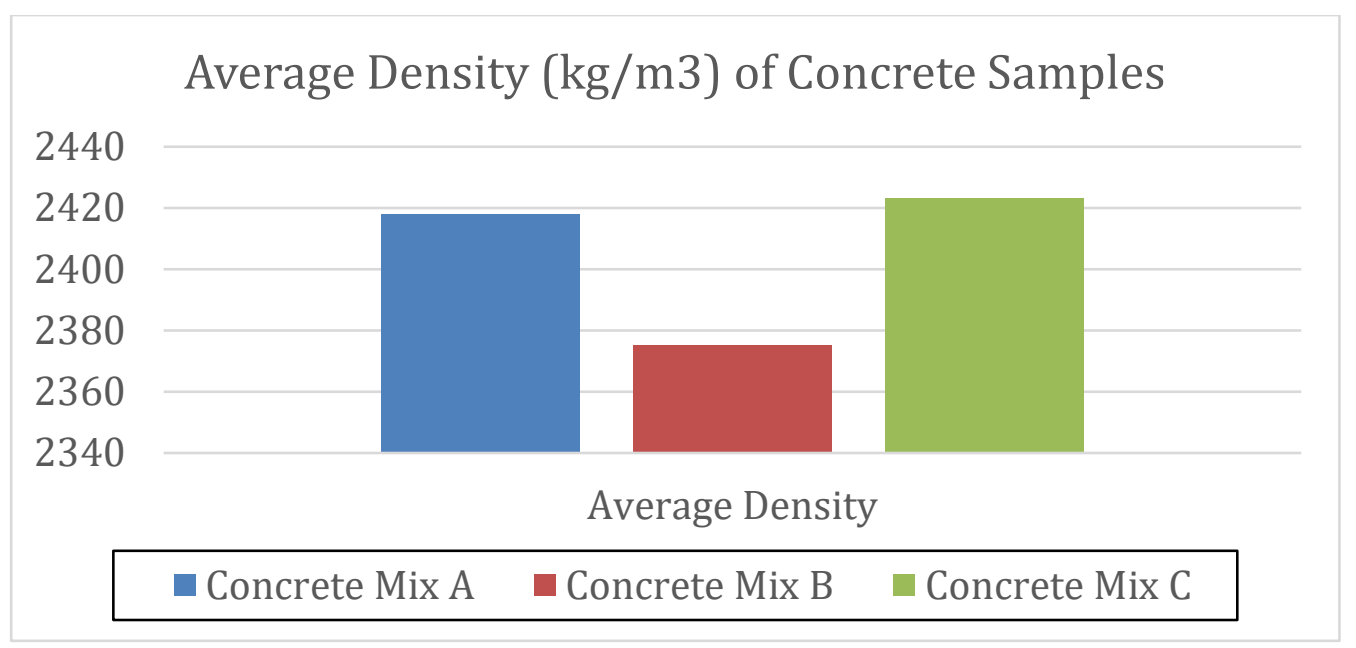

Figure 1. Average density of concrete samples

The compressive strength of the samples was tested out three times on the $7^{\text {th }}, 14^{\text {th }}$ and the $28^{\text {th }}$ day. It is measured by using the compression-testing machine. The compression strength is calculated from the failure load divided by the cross-sectional area resisting the load acting on the sample and the values are reported in megapascals (MPa). The samples with the presence of $\mathrm{CO}_{2}$ provided a highest compressive strength, followed by the samples without the presence of $\mathrm{CO}_{2}$ and finally the samples with $\mathrm{CO}_{2}$ that had the longest gas exposure duration. The table and the graph below illustrate the changes in the compressive strength of the concrete in 28 days.

TABLE III. COMPRESSIVE STRENGTH OF CONCRETE SAMPLES

\begin{tabular}{|c|c|c|c|}
\hline No. of Days & Concrete Mix A & Concrete Mix B & Concrete Mix C \\
\hline 7 days & $15.72 \mathrm{MPa}$ & $7.96 \mathrm{MPa}$ & $14.64 \mathrm{MPa}$ \\
\hline 14 days & $20.72 \mathrm{MPa}$ & $12.27 \mathrm{MPa}$ & $21.33 \mathrm{MPa}$ \\
\hline 28 days & $24.36 \mathrm{MPa}$ & $16.32 \mathrm{MPa}$ & $26.14 \mathrm{MPa}$ \\
\hline
\end{tabular}

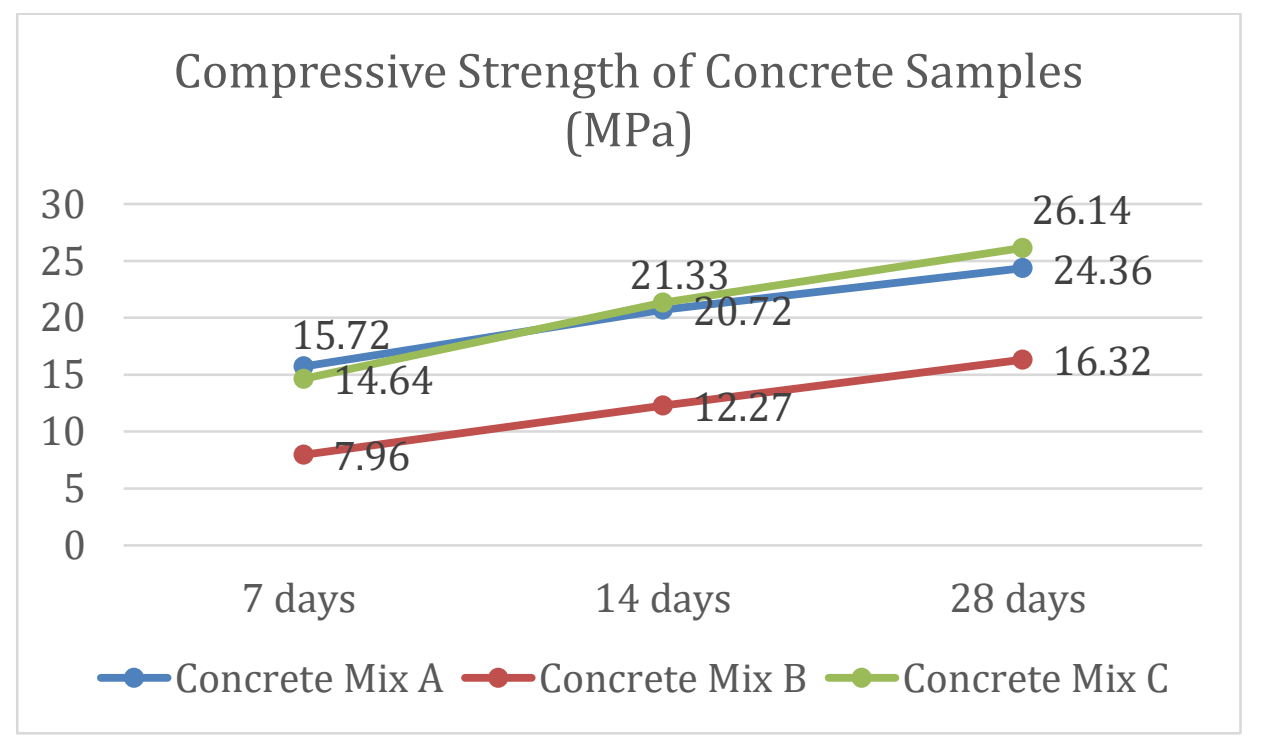

Figure 2. Compressive strength of concrete samples on 7, 14 and 28 days 


\section{CONCLUSIONS}

The aim of this research was to determine the effects of carbon dioxide sequestration on concrete and the compressive strength of the concrete. This was done by allowing $\mathrm{CO}_{2}$ to be mixed with fresh concrete during the mixing phase of concrete. The spraying of $\mathrm{CO}_{2}$ was done in an enclosed concrete mixture in order to provide more effective results. An open mixture would only allow more of the $\mathrm{CO}_{2}$ gas to be released to the atmosphere and disrupt the chemical reaction between the fresh concrete and carbon dioxide. Also, it was found that the concrete mixture exposed to $\mathrm{CO}_{2}$ requires more water compared to concrete mixture without exposure to the $\mathrm{CO}_{2}$ gas injection because of the reduction of water during the chemical reaction. The duration of the $\mathrm{CO}_{2}$ gas injection was also modified accordingly as a longer duration would only make the concrete mix seem drier.

In regards to the compressive strength it is also proven that sequestration of $\mathrm{CO}_{2}$ increases the compressive strength of the concrete. $\mathrm{CO}_{2}$ sequestered concrete was found to have a reasonably higher compressive strength compared to concrete without $\mathrm{CO}_{2}$. These are due to additional water and also the effectiveness of the project whereby it is based on the ability of the nanosized $\mathrm{CaCO}_{3}$ to fill the voids of the concrete. This also explains why the density of $\mathrm{CO}_{2}$ sequestered concrete is higher than of concrete without $\mathrm{CO}_{2}$. Therefore, it can be concluded that $\mathrm{CO}_{2}$ sequestered concrete improves the compressive strength of concrete by allowing to achieve higher compressive strength at a faster time period compared to concrete without $\mathrm{CO}_{2}$.

\section{ACKNOWLEDGEMENT}

The authors wish to acknowledge YCU Grant 201901001YCU/11 for the sponsorship for publication of this paper.

\section{REFERENCES}

[1] Robbie M. Andrew. 2018. Global CO2 emissions from cement production. Pg $195-217$.

[2] Y. Shao, S. Monkman and A. J. Boyd. 2010. Recycling carbon dioxide into concrete: a feasibility study.

[3] Josh Brown, P.Eng, MASc. 2016. Ready Mixed Concrete Technology System. CarbonCure Technologies.

[4] Sean Monkman. 2018. TECHNICAL NOTE - Types of concrete carbonation. CarbonCure Technologies.

[5] Sean Monkman. 2018. TECHNICAL NOTE - Chemistry of Fresh Concrete Carbonation. CarbonCure Technologies.

[6] Fereidoon Moghadas Nejad, Ehsan Geraee \& Ali Reza Azarhoosh (2018): The effect of nano calcium carbonate on the dynamic behaviour of asphalt concrete mixture, European Journal of Environmental and Civil Engineering.

[7] Mohd Tanjeem Khan, Khan Rahim Saud, Karadia Ashraf M.Irfan, Shaikh Ibrahim. 2018. Curing of Concrete by Carbon Dioxide. Vol: 05 Issue:04.

[8] John Kline, Charles Kline. 2018. CO2 Capture from Cement Manufacture and Reuse in Concrete. CIC-0037. 